\title{
Evolution of the Arthroscopic Treatment of Chronic Lateral Epicondylitis-Preliminary Result
}

\author{
Jesús Ortega ${ }^{1}$, Saúl Apóstol-González ${ }^{1,2 *}$ and Piero Pizzolla ${ }^{1}$ \\ ${ }^{1}$ Traumatology Specialist, San Diego Valley Medical Center, Venezuela \\ ${ }^{2}$ Traumatology, Arthroscopy and Foot Surgery Department, IEQ Los Mangos Clinic, Venezuela
}

*Corresponding author: Saúl Apóstol-González Dr, Medical Director, Traumatology, Arthroscopy and Foot Surgery Department, 110 Street, IEQ Los Mangos Clinical Building, Floor 3 office 3-4, Los Mangos Urbanization, Valencia, Venezuela

Submission: 眥 March 01, 2018; Published: 眥 March 13, 2018

\section{Abstract}

Objective: To assess the outcome of arthroscopic release in patients with cronicalchronic lateral epicondylitis.

Materials and methods: Arthroscopic release in three patients with lateral epicondylitis was performed. The Mayo Elbow Performance Index (or Mayo Elbow Performance score) was used pre and post surgical treatment. Sample: Two females and one male. The patients were principal labourers and not athletes. Patients had significant pain and pain was the principal symptom that affected the score of the performance index.

Results: Scores on the performance index improved after surgery. No neurological complications were reported and early return to normal daily activities was noted.

Conclusion: Arthroscopic treatment was an alternative safe and effective method for treating chronic lateral epicondiyitis in three cases. This method makes it possible to simultaneously scan the articulation to diagnostic and treatment associated diseases. It is necessary most wide assays and comparative studies for establish sure treatment protocols.

Keywords: Lateral epicondylitis; Pain; Elbow; Arthroscopy

\section{Introduction}

Lateral epicondylitis (tennis elbow) is a common entity in the general population. It has an incidence of 4-7 per 1000 inhabitants per year. Recent studies highlight that between $1-3 \%$ of the population will suffer discomfort during the course of life [1]. It affects individuals between 35 and 50 years. The condition occurs in people of various trades from housewives to athletes. Although the tennis elbow can present itself acutely, its behavior in general is insidious, secondary to repetitive movements of extension of the wrist and prono-supination of the forearm. Lateral tendinosis is defined as a microscopic tear of the short radial extensor carpi (or extensor carpi radialis brevis), which is located on the lateral proximal side, below the tendon of the long radial extensor of the carpus (extensor carpi radialis longus), covers the radial head, and runs between the long supinator and the long radial extensor of the carpus $[1,2]$. The short radial extensor of the carpus has a weak biomechanical point where it connects to the joint capsule without covering the supinator muscle. This is an essential etiological point that makes it vulnerable for micro-distraction [2].

Majority of patients (80\%) improve with conservative treatment that includes: NSAIDs, orthotics, physiotherapy, local infiltration with steroids, shock waves, etc. However, when the discomfort becomes recalcitrant and limiting, without improvement after 6 months of conservative treatment, the surgical indication treatment is indicated. Recently, the arthroscopic release of the tennis elbow has become popular. The debridement of the degenerated tendon, the capsular release and the underlying decortication is the most commonly used technique [1,3-6]. The best increased knowledge of the elbow anatomy and the technical improvement and safety of the arthroscopic portals have increased the reports of the arthroscopic treatment of lateral epicondylitis. The present work describes the technique and reports the preliminary results of the arthroscopic treatment of lateral epicondylitis in three patients.

\section{Materials and Methods}

The arthroscopic treatment of lateral epicondylitis is described in three patients. Two women and one man, presented with pain in the right elbow. The patients had more than 6 months of conservative treatment consisting of anti-inflammatory analgesics, local infiltration with depot steroids (diprospan), and use of orthotics and physiotherapy. Each patient's history is described in Table 1. 
Table 1: Summary table of patients studied.

\begin{tabular}{|c|c|c|c|c|c|c|}
\hline Patients & Sex & Age & Occupation & Previous Treatments & $\begin{array}{c}\text { Scale C Mayo } \\
\text { Preoperative }\end{array}$ & $\begin{array}{c}\text { Scale C Mayo } \\
\text { Postoperative }\end{array}$ \\
\hline No 1 & F & $52 \mathrm{a}$ & Housewife & $\begin{array}{c}\text { Aines Local infiltration with Diprospan } \\
\text { Physiotherapy Ortesis }\end{array}$ & 55 puntos & 100 puntos \\
\hline No 2 & F & $45 \mathrm{a}$ & Teacher & Aines Local infiltration with Diprospan & 65 puntos & 95 puntos \\
\hline No 3 & M & $32 \mathrm{a}$ & $\begin{array}{c}\text { Bank } \\
\text { cashierman }\end{array}$ & $\begin{array}{c}\text { Aines Local infiltration with Diprospan } \\
\text { Physiotherapy Ortesis }\end{array}$ & 60 puntos \\
\hline
\end{tabular}

\section{Surgical technique}

Type of anesthesia: General anesthesia was performed. Under anesthesia, ranges of mobility and stability of the elbow were examined.

\section{Patient's position}

The patient was placed in lateral decubitus with the side of the operation facing upwards with the elbow in $90^{\circ}$ flexion (Figure 1). The pneumatic tourniquet was placed in the proximal third of the ipsilateral arm. The arm rested on a padded support, and care was taken to prevent the support from pressing the antecubital fossa and the anterior neurovascular structures. Marking of the surface and location of portals can be viewed in Figure $1 \& 2$.

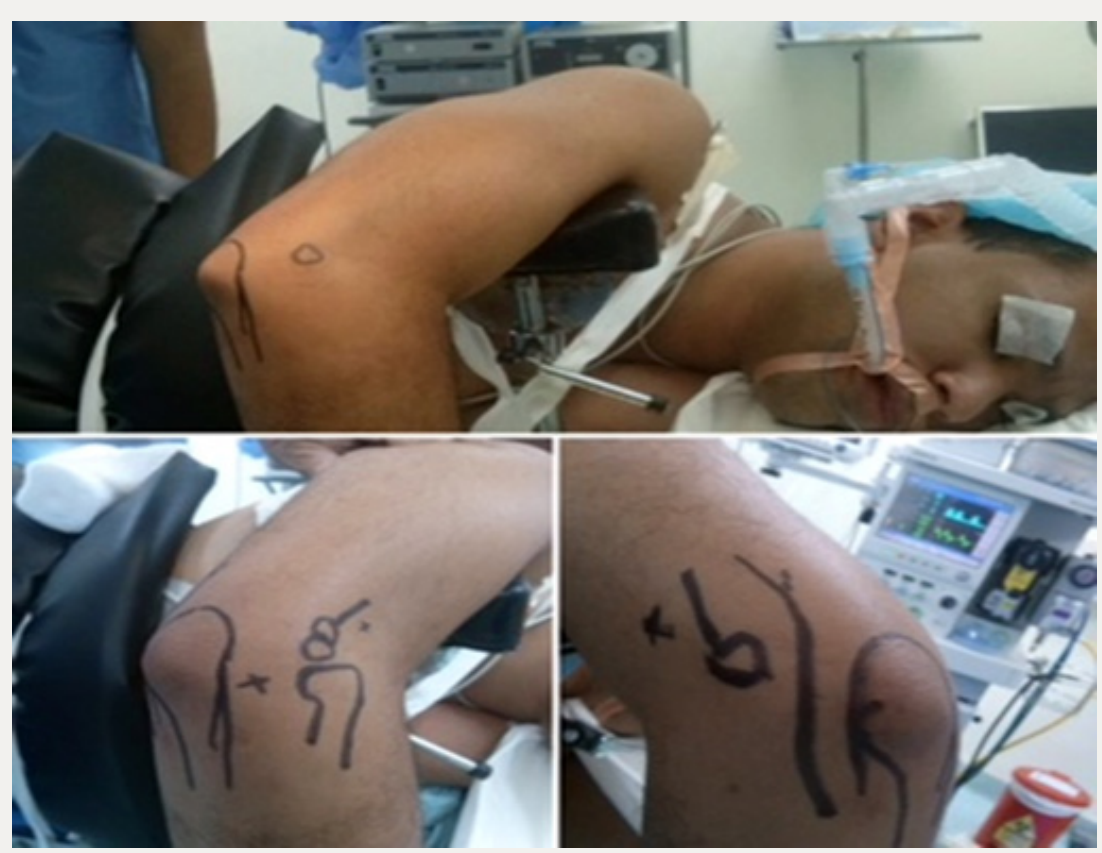

Figure 1: Positioning of patient and marking of the elbow for reference of portals.

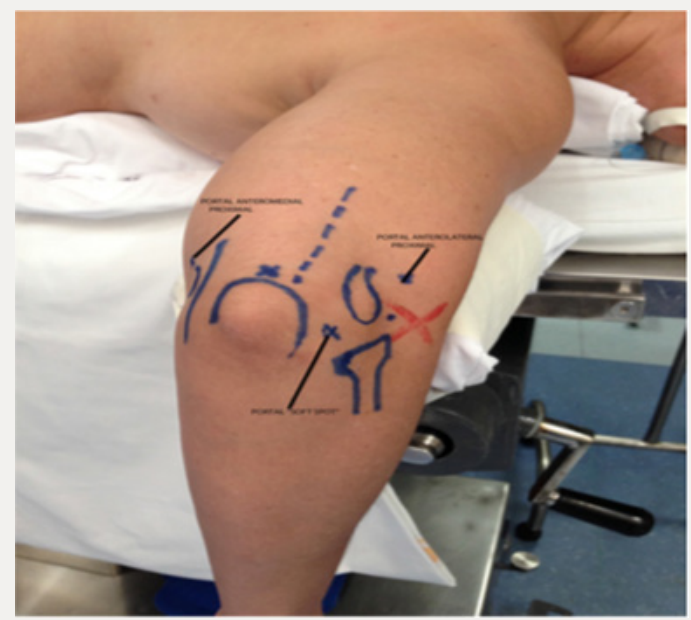

Figure 2: Schematization of portals in the skin of the elbow. 


\section{Procedure}

20 to 30 milliliters of physiological solution was injected into the joint space of the elbow. INTERNAL ANTERO PORTAL (originally described by Andrew and Carson), is located $2 \mathrm{~cm}$ anterior and $2 \mathrm{~cm}$ distal to the medial epicondyle or epitrochlea; with scalpel number 11 the skin was incised, dissection is was performed with a straight clamp to later insert the arthroscope cannula with blunt initiator. The joint is distended with physiological solution fluid by using an initial pressure pump of $30 \mathrm{mmHg}$. With a $4.0 \mathrm{~mm}$ lens, diagnostic arthroscopy was performed to determine the presence of joint pathology, free bodies and other associated pathologies. The lesion and the extension of the carpal short radial extensor complex were classified.

Three types of injuries can be found:

Grade 1: Fraying of the capsule

Grade 2: A linear tear

Grade 3: Retraction and avulsion of the tendon

\section{Middle Antero External Portal}

The radio-humeral joint was located at the lateral epicondyle. From there a point located $3 \mathrm{~cm}$ distal and $1 \mathrm{~cm}$ anterior from outside to inside is marked and a guide needle is inserted. The intraarticular needle is visualized. If the position was correct, an incision was made with a scalpel No 11. The blunt tester was introduced. The external joint capsule and the inferior surface of the extensor carpi radialis tendon short to its origin in the lateral epicondyle were evaluated. With the tip of the synovial shaver $(4.5 \mathrm{~mm})$, the abnormal tissue that is deteriorated, with changes in coloration and with different degrees of fibrous tears, was debrided; the capsule was debrided and the insertion of the short radial extensor tendon of the carpus was released where the pathology was observed and continued from below to its origin (Figure 3). With a burr shave, the epicondyle was decorticated until it bled. Subsequently, the patient was evaluated at the 3rd and 10th postoperative days. Then, monthly and quarterly consultations were completed for at least 6 months. The Mayo Elbow Performance Index was used for the clinical and functional assessment (Table 2).

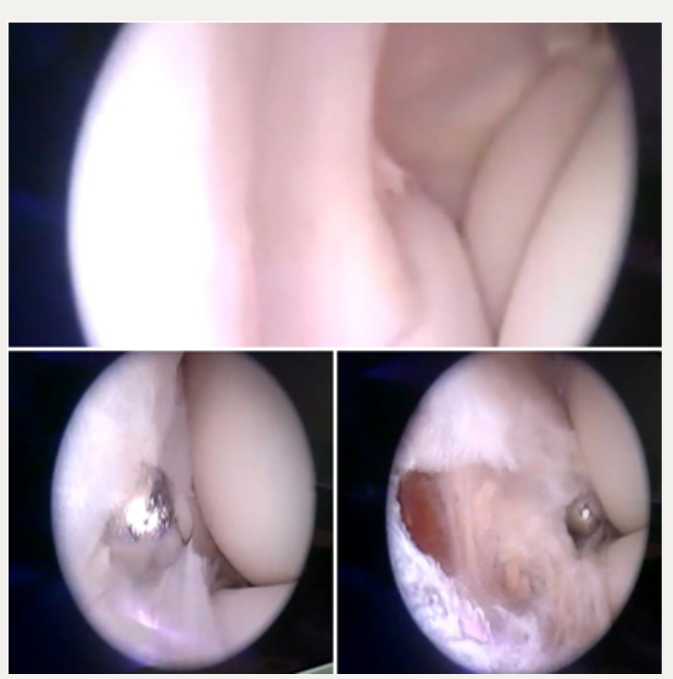

Figure 3: Arthroscopic examination of the elbow. Articular review in search of associated pathologies. Lower images show capsular debridement and of the affected area of the short extensor of the carpus to visualize muscle fibers of the long supinator.

Table 2: Elbow Mayo elbow performance index.

\begin{tabular}{|c|c|}
\hline Category & Score \\
\hline \multicolumn{2}{|c|}{ Pain } \\
\hline No & 45 \\
\hline Leve & 30 \\
\hline Moderado & 15 \\
\hline Grave & 0 \\
\hline \multicolumn{2}{|c|}{ Movement Range } \\
\hline More than 100 grades & 20 \\
\hline $50-100$ grades & 15 \\
\hline Lower than 50 grades & 5 \\
\hline \multicolumn{2}{|c|}{ Stability } \\
\hline
\end{tabular}

\begin{tabular}{|c|l|}
\hline Stable & 10 \\
\hline Slight instability & 5 \\
\hline Important instability & 0 \\
\hline \multicolumn{2}{|c|}{ Function } \\
\hline Can brush the hair & 5 \\
\hline Can eat & 5 \\
\hline Can perform personal Hygiene & 5 \\
\hline The stockings can be placed & 5 \\
\hline The footwear can be placed & 5 \\
\hline
\end{tabular}

Result: Excellent: 90-100; Good: 75-89; Regular: 60-74; bad or poor: less than 59 points. 


\section{Results}

Three patients ( 2 women and one man), who did not respond to conservative treatment for 6 months, were treated in the current report. One patient is a housewife and another was an educator (teacher). The male patient performs as a bank teller. The average preoperative score was 60 . The symptom that had the highest incidence in the score was intense pain. The average surgery time was 70 minutes. There were no neurological injuries. There were no additional findings to the vision of the joint. The patients were reintegrated into their activities at 3 weeks postoperatively. Pain as a sign and capital symptom improved significantly within a few days of surgery. The rating scale score was raised to excellent levels (over 90). Table 1 shows the summary of results.

\section{Discussion}

Lateral epicondylitis or tennis elbow is a common pathology in the general population. Despite its nominal etymology, it is not a disease that is exclusive to athletes. The patients in this report did not perform sport activities. They are patients with normal daily activities. The literature describes that the pathology for this condition in general improves with conservative treatment. In the present report, it was decided to perform surgery in view of the poor results with conservative measures. Elbow arthroscopy, besides being a less invasive procedure preserves the integrity of the skin and underlying tissues, causes less inflammatory reaction, and allows assessing the joint in its entirety for inspecting and ruling out associated pathologies. Many authors [1,6] have described good results with early reintegration to the daily activity after the arthroscopic treatment of the tennis elbow. Miyazaki et al. [7] reported results of 20 patients operated over a period of 8 years, obtaining 65\% excellent results. One patient presented discomfort associated with reflex sympathetic dystrophy (Complex regional pain type 2). Bercelo et al. [4] reported a patient with associated paresthesia in the lateral forearm area. None of our three patients showed signs of neurological injury. Dunkow et al [8] treated surgically 47 elbows in 45 patients, 24 with classic open surgery and 23 with percutaneous tenotomy. They reported that the latter had a significantly better outcome than formal open release. Yan et al. [9] treated 28 elbows of 26 patients, 13 for open surgery and 15 with arthroscopy, and reported excellent results and good results in both groups. Ernten et al. [3] believe that lateral epicondyle sensitivity may be related to arthroscopic decortication. In the literature, it is described that perforation or decortication of the lateral epicondyle can cause sensitization of the area for an extended period after surgery $[10,11]$. Perhaps this can be prevented by avoiding the decortication of the epicondyle, in view of good results only with the debridement of injured soft tissues. When the discomfort does not improve after exhausting the conservative measures for at least 6 months, arthroscopic treatment is an option for lateral epicondylitis, good results can be obtained with an early return to work without restriction [4]. In conclusion we can say that arthroscopy is becoming a safe option every day for the treatment of recalcitrant lateral epicondylitis, with few complications. Additionally, the exploration of the articulation makes it possible to diagnose and treat associated pathologies, resolving them with a minimally invasive technique. It is necessary to design more comprehensive and comparative studies to establish safe treatment protocols.

\section{References}

1. Matache, Berdusco R, Momoli F, Lapner LC, Pollock JW (2016) A randomized, double-blind sham controlled trial on the efficacy of arthroscopic tennis elbow release for the management of chronic lateral epicondylitis Bogdan A. BMC Musculoskelet Disord 17: 239.

2. Inagaki K (2013) Current concepts of elbow-joint disorders and their treatment. J Orthop Sci 18(1): 1-7.

3. Ertem K, Ergen E, Yoloğlu S (2015) Functional outcomes of arthroscopic treatment of lateral epicondylitis. Acta Orthop Traumatol Turc 49(5): 471-477.

4. Terra BB, Rodrigues LM, Filho AN, de Almeida GD, Cavatte JM, et al. (2015) Arthroscopic treatment for chronic lateral epicondylitis. Rev Bras Ortop 50(4): 395-402.

5. Babaqi AA, Kotb MM, Said HG, Abdel Hamid MM, ElKady HA, et al. (2014) Short-term evaluation of arthroscopic management of tennis elbow; including resection of radio-capitellar capsular complex. J Orthop 11(2): 82-86.

6. Miyazaki AN, Fregoneze M, Santos PD, da Silva LA, Pires DC, et al. (2010) Evaluation of the results from arthroscopic treatment of the lateral epicondilitis. Rev Bras Ortop 45(2): 136-140.

7. Miyazaki AN, Fregoneze M, Santos PD, Silva LA, Pires DC, et al. (2010) Avaliação dos resultados do tratamento artroscópico da epicondilite lateral. Rev Bras Ortop 45(2): 136-140.

8. Dunkow PD, Jatti M, Muddu BN (2004) A comparison of open and percutaneous techniques in the surgical treatment of tennis elbow. J Bone Joint Surg Br 86: 701-704.

9. Yan H, Cui GQ, Liu YL, Xiao J, Yang YP, et al. (2009) A randomized comparison of open and arthroscopic Nirschl debridement for refractory lateral epicondylitis. Zhonghua Wai Ke Za Zhi 47(12): 888-891.

10.Zingg PO, Schneeberger AG (2006) Debridement of extensors and drilling of the lateral epicondyle for tennis elbow: a retrospective followup study. J Shoulder Elbow Surg 15(3): 347-350.

11. Kelly EW, Morrey BF, O’Driscoll SW (2001) Complications of elbow arthroscopy. J Bone Joint Surg Am 83-A(1): 25-34.
Creative Commons Attribution 4.0 International License

For possible submissions Click Here
Submit Article

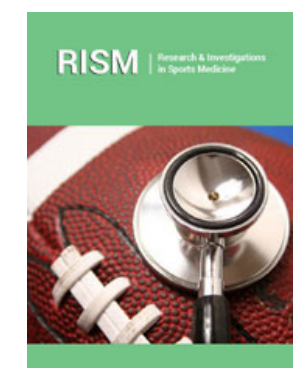

Research \& Investigations in Sports Medicine

\section{Benefits of Publishing with us}

- High-level peer review and editorial services

- Freely accessible online immediately upon publication

- Authors retain the copyright to their work

- Licensing it under a Creative Commons license

- Visibility through different online platforms 